\title{
RESEARCH
}

Open Access

\section{Is enhancing the professionalism of healthcare providers critical to tackling antimicrobial resistance in low- and middle- income countries?}

Mishal S. Khan ${ }^{1,2^{*}+}$ (D), Sothavireak Bory ${ }^{3 \dagger}$, Sonia Rego ${ }^{1}$, Sovanthida Suy ${ }^{4}$, Anna Durrance-Bagale ${ }^{1}$, Zia Sultana ${ }^{2}$, Sophea Chhorn', Socheata Phou ${ }^{4}$, Chanra Prien ${ }^{3}$, Sotheara Heng ${ }^{5}$, Johanna Hanefeld ${ }^{1}$, Rumina Hasan ${ }^{2,6}$ and Vonthanak Saphonn ${ }^{5}$

\begin{abstract}
Background: Healthcare providers' (HCPs) professionalism refers to their commitment and ability to respond to the health needs of the communities they serve and to act in the best interest of patients. Despite attention to increasing the number of HCPs in low- and middle-income countries (LMIC), the quality of professional education delivered to HCPs and their resulting professionalism has been neglected. The Global Action Plan on Antimicrobial Resistance (AMR) seeks to reduce inappropriate use of antibiotics by urging patients to access antibiotics only through qualified HCPs, on the premise that qualified HCPs will act as more responsible and competent gatekeepers of access to antibiotics than unqualified HCPs.

Methods: We investigate whether weaknesses in HCP professionalism result in boundaries between qualified HCPs and unqualified providers being blurred, and how these weaknesses impact inappropriate provision of antibiotics by HCPs in two LMIC with increasing AMR-Pakistan and Cambodia. We conducted 85 in-depth interviews with HCPs, policymakers, and pharmaceutical industry representatives. Our thematic analysis was based on a conceptual framework of four components of professionalism and focused on identifying recurring findings in both countries.

Results: Despite many cultural and sociodemographic differences between Cambodia and Pakistan, there was a consistent finding that the behaviour of many qualified HCPs did not reflect their professional education. Our analysis identified five areas in which strengthening HCP education could enhance professionalism and reduce the inappropriate use of antibiotics: updating curricula to better cover the need for appropriate use of antibiotics; imparting stronger communication skills to manage patient demand for medications; inculcating essential professional ethics; building skills required for effective collaboration between doctors, pharmacists, and lay HCPs; and ensuring access to (unbiased) continuing medical education.

(Continued on next page)
\end{abstract}

\footnotetext{
* Correspondence: mishal.khan@lshtm.ac.uk

${ }^{\dagger}$ Mishal S. Khan and Sothavireak Bory are joint first authors.

${ }^{1}$ Faculty of Public Health \& Policy, London School of Hygiene \& Tropical

Medicine, 15-17 Tavistock Place, London WC1H 9SH, United Kingdom

${ }^{2}$ Aga Khan University, Karachi, Pakistan

Full list of author information is available at the end of the article
}

(c) The Author(s). 2020 Open Access This article is distributed under the terms of the Creative Commons Attribution 4.0 International License (http://creativecommons.org/licenses/by/4.0/), which permits unrestricted use, distribution, and reproduction in any medium, provided you give appropriate credit to the original author(s) and the source, provide a link to the Creative Commons license, and indicate if changes were made. The Creative Commons Public Domain Dedication waiver (http://creativecommons.org/publicdomain/zero/1.0/) applies to the data made available in this article, unless otherwise stated. 
(Continued from previous page)

Conclusions: In light of the weaknesses in HCP professionalism identified, we conclude that global guidelines urging patients to only seek care at qualified HCPs should consider whether HCP professional education is equipping them to act in the best interest of the patient and society. Our findings suggest that improvements to HCP professional education are needed urgently and that these should focus not only on the curriculum content and learning methods, but also on the social purpose of graduates.

Keywords: Medical education, Professionalism, Cambodia, Pakistan, Antimicrobial resistance

\section{Background}

The urgent need to increase the number of healthcare professionals (HCPs) in low- and middle-income countries (LMIC) has been highlighted by international agencies and has captured the attention of some LMIC politicians [1-5]. Thus, in recent decades, there has been an increase in the number of HCPs entering the workforce. Globally, it is estimated that 400000 doctors and 550000 nurses/midwives graduate every year [6]. However, the quality of professional education delivered to HCPs, and the social impact of the increased number of HCPs, has received much less attention [7]. For instance, the increased number of HCPs does not address concerns about major gaps in their knowledge and professionalism, including technical skills and essential values and behaviours that enable them to benefit society $[1,6$, 8]. In LMIC, these concerns are driven by evidence on variations in class sizes, questionable examination procedures, urban bias in the location of HCP education institutes, and the lack of regulation over teaching content, methods, and standards [6, 9-11].

HCP commitment and ability to respond to the health needs of the communities they serve and to act in patients' best interest is critical for numerous reasons. It has a major impact on the quality and cost of care that patients receive during transactions characterised by uncertainty, informational asymmetry, and buyer vulnerability [12]. Beyond impacts on individuals, the education and role of HCPs affect global health security owing to the increasing cross-national transfer of health expertise, health services, and infectious diseases $[13,14]$. For example, in the United States of America, Canada, and most nations in Western Europe, a quarter of physicians acquire medical training outside the country they practise in [6]. Finally, and most closely related to aims of this study, it is essential to take into account the professionalism of HCPs when formulating global health guidelines that rely on the technical and ethical competence of HCPs in LMIC for successful implementation.

The Global Action Plan on Antimicrobial Resistance (AMR)-adopted by the membership of the World Health Organization (WHO), the Food and Agriculture Organization of the United Nations, and the World Organisation for Animal Health in 2015-is a salient example of such a global guidance document. LMIC are currently attempting, with some challenges, to implement it $[15,16]$. A key pillar of the Global Action Plan on AMR is optimising the use of antimicrobial agents, and the guidelines urge patients to access antimicrobials only through qualified HCPs. The implicit and critical assumption behind this strategy is that qualified HCPs will prescribe or dispense antibiotics responsibly and that directing patients towards qualified HCPs, and away from unqualified HCPs, will reduce inappropriate use of antimicrobials [15]. However, when HCP professionalism is lacking, boundaries between qualified HCPs and unqualified providers can be blurred [17, 18]; for example, qualified providers may routinely fail to follow treatment guidelines [19] or regulations around prescribing [20], and informal providers may demonstrate more empathy towards patients than qualified HCPs [17, 21]. We therefore hypothesise that weaknesses in the professionalism of HCPs-including doctors, pharmacists, and nurses-will have an impact on inappropriate use of antibiotics, and we investigate this in two LMIC, Pakistan and Cambodia.

\section{Professionalism and social accountability of HCPs}

There is some variation in the conceptualisation of professionalism of HCPs among scholars, with differences centred around whether professionalism is connected to HCPs' inner morality or to observable behaviours or to integration into a community of practice [22]. Two core attributes can be identified across conceptualisations, which we term competence and care [22-26]. Competence encompasses both the technical knowledge and clinical skills to provide high-quality care, and the ability to collaborate with relevant HCPs and policymakers to ensure that the health system works optimally. Care includes two distinct components, intrinsic and extrinsic. The intrinsic component centres on altruism and ethical conduct, including a 'commitment to placing the interests of the patient ahead of those of the professional' [27]. The extrinsic component is a demonstration to the patient and their caregivers, through effective communication, of empathy, trustworthiness, and compassion such that the patient has confidence in the HCP's advice. 
We summarise our conceptualisation of the components of HCP professionalism in Fig. 1.

There are opposing views on the goals of HCP professional education. One view is that HCP education is a public good, designed to develop a socially responsive health workforce that meets the health needs of the communities it serves. This could encompass producing graduates that not only have relevant knowledge, skills, and values but also the drive to influence the system in a positive direction. However, in some contexts, HCP education is increasingly seen as a private good geared towards helping those who make substantial investments to pay for the lengthy postgraduate qualification to maximise social mobility and personal success $[28,29]$. Concerns have been raised about HCP education focusing too closely on the acquisition of biomedical information that directs students away from developing the skills and attitudes required to address the determinants of health in their patients. However, innovations and improvements have concentrated on curriculum content and learning methods, rather than on the social purpose and moral obligations of the curriculum [11].

\section{Methods}

\section{Study setting}

We selected Pakistan and Cambodia for this study because the countries differ in terms of socio-cultural context and size, but are experiencing similar dynamics with respect to the evolution of the health and $\mathrm{HCP}$ education systems. Pakistan, a predominantly Muslim country in South Asia, is the sixth most populous in the world, and Cambodia, located in the southern portion of the Indochina Peninsula in Southeast Asia, has a small, predominantly Buddhist population of approximately 15 million [30]. The majority of patients in Cambodia and Pakistan seek care from private HCPs, with approximately $60-65 \%$ paying out of pocket charges for healthcare [31-33]. In both countries, HCP education is increasingly provided by private institutions, and existing public sector institutions are typically under-resourced
[34]. This partly reflects a low investment in health, including HCP education; 6\% of Cambodia's GDP and 3\% of Pakistan's GDP are invested in health [35]. Curricula used in HCP education are criticised for not being updated frequently enough, having been influenced by the colonisation of Pakistan and Cambodia by the British and French, respectively [36]. We were able to examine whether these similarities in underlying systemic issues manifest consistently in the professionalism of $\mathrm{HCPs}$ even when socio-cultural features differ. Here, we provide a brief overview of relevant contextual factors in our study countries.

\section{Cambodia}

The current state of health and health professional education has been drastically shaped by the systematic killing of intellectuals-including qualified HCPs-during the Khmer Rouge regime and the consequent civil war [37, 38]. In 1979, only 45 medical doctors, 26 pharmacists, 28 dentists, and 128 medical students had survived the Khmer Rouge regime [39]. After the genocide, no professors, of any faculty, remained in Cambodia, and medical, nursing, and pharmacy training, which was fairly comprehensive until this period, was severely disrupted and is still recovering [34, 40]. Cambodia's leading public medical school, the University of Health Sciences, resumed operation in 1980.

There are 18 HCP educational institutions in Cambodia. There are two public medical schools, and a Ministry of Health report from 2018 indicates that there are three private medical schools, although news reports suggest that the number is higher, as several private medical schools have opened in recent years [41, 42]. Entrance exams for medical schools have recently been the subject of controversy and protests, as the process to reduce bribery and cheating has resulted in fewer students passing the exams $[43,44]$.

A basic medical qualification is granted after 6 years of general medical education and 2 years of clinical rotations across four disciplines (general medicine, surgery,
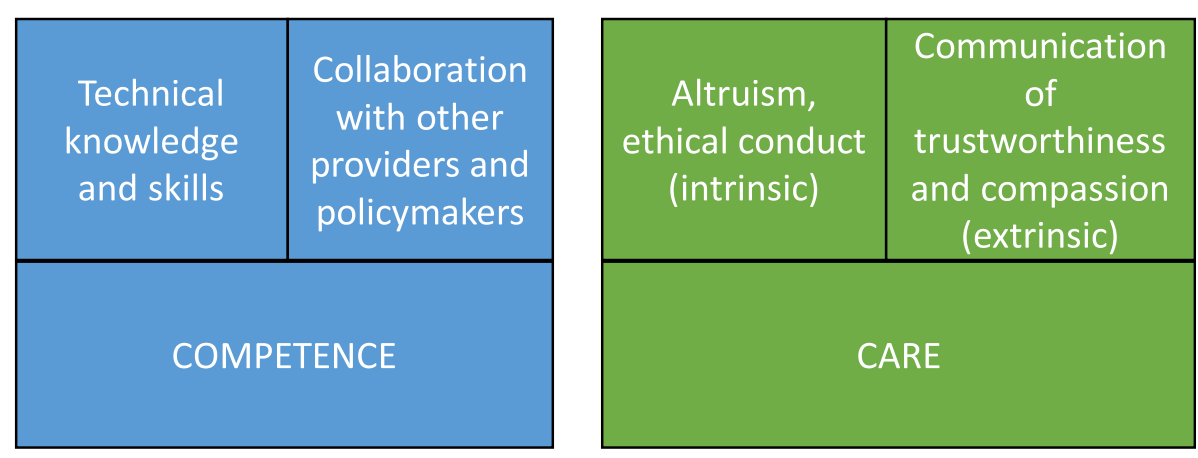

Fig. 1 Components of HCP professionalism 
gynaecology, and paediatrics). Upon completion, students are awarded an MD. To become qualified to practise medicine legally, doctors must pass the national exit examination and register with the Cambodian Medical Council (CMC). Registration with the CMC lasts for between 1 and 3 years depending on the category of doctor, and re-registration requires completion of some continuing medical education (CME) courses. The extent to which these registration requirements for doctors are enforced is unclear; the CMC website 'strongly encourages' timely registration but does not mention specific penalties for failure to do so.

A pharmacy degree takes 5 years, and students must pass a national licencing exam, but can also continue their studies to become a Doctor of Pharmacy, which takes an additional 3 years. Other professional diplomas (nurses, midwives, and biomedical technicians) take 3 years [45].

\section{Pakistan}

In line with its bigger population size, Pakistan has a much larger medical education system than Cambodia, with 114 medical colleges of which 44 are public and 70 are private [46]. The number of graduates from medical colleges has increased from 500 in 1947 at the time of independence to approximately 200000 . This sharp increase is attributed due to the growth of private medical schools from one in 1981 to 32 in 2010 and 55 at present [47]. Concerns about the standards of healthcare professional education, excessive fees charged by private medical colleges, and corruption have resulted in Pakistan's regulatory body-the Pakistan Medical \& Dental Council (PMDC)-being suspended on 20 October 2019, and major reforms are currently underway. We describe the training and licencing system operating since the 1960s (including at the time of the study).

Basic medical training leading to an MBBS degree lasts 5 years. After a 1-year internship (also referred to as a house officer job) in a hospital recognised by the Pakistan Medical \& Dental Council (PMDC), and after applying for a medical licence from the PMDC, doctors can work as general practitioners [48]. Registration with the PMDC needs to be renewed every 2 years, but renewal does not require any additional exams, only payment of a fee. Unlike Cambodia, there is no national or provincial exam at the MBBS level. However, the specialist examination for Fellowship of the College of Physicians and Surgeons of Pakistan is a national-level examination. The PMDC documents the minimum content that medical and dental training cover, although regular monitoring of educational institutions has not been sustained.

Pharmacy training takes 5 years, and students are awarded a Doctor of Pharmacy degree upon completion
[49]. Like Cambodia, there is no enforcement of compulsory CME, although there are opportunities for CME through the College of Physicians and Surgeons [50].

\section{Study population}

We conducted a total of 85 in-depth interviews with HCPs (doctors, pharmacists, nurses, and medicine sellers), government health agencies, national AMR technical policy advisers, pharmaceutical industry staff, nongovernmental organisations working on healthcare, and local representatives of international policy bodies such as the WHO. There was a fairly even balance between countries with 44 interviews in Cambodia and 39 in Pakistan. We used a combination of purposive and snowball sampling to identify interviewees and ensured that all policymakers and technical advisers who were nominated as being influential with respect to policies on access to medicines and regulation of HCP clinical activities were approached for an interview.

\section{Data collection and analysis}

We followed the SRQR reporting guidelines for qualitative studies [51]. Interviews were conducted by two members of the research team, with one Cambodian or Pakistani researcher being involved in each interview. Except in a few cases, where consent for recording was not given, interviews were recorded and detailed interview notes were taken. Interviews were transcribed verbatim and professional translators were used to translate transcripts into English when interviews were conducted in Khmer or Urdu. Participants were de-identified in the transcripts, and we organised and coded each transcript line by line in NVivo (v12). Guided by our conceptualisation of the components of HCP professionalism summarised in Fig. 1, we conducted a thematic analysis employing an interpretive approach in which identified themes are supported by excerpts from the raw data to ensure that data interpretation remains directly linked to the words of the participants [52]. Themes that were identified consistently across both countries were categorised as core themes and are discussed in this paper. After collating our initial findings, we sought feedback from the interviewees and incorporated their input into our analysis.

\section{Results}

Despite the many cultural and sociodemographic differences, there were striking similarities in the dynamics underlying inappropriate use of antimicrobials by HCPs in Pakistan and Cambodia. In line with our hypothesis, we found that there was little reported difference between the practices of 'unqualified doctors' (quacks) and qualified doctors with respect to following domestic guidelines on the use of antibiotics, and both qualified 
pharmacists and unqualified drug sellers routinely dispensed antibiotics without a prescription. Thus, in both countries, the behaviour of many qualified HCPs did not reflect their professional education.

I have seen the biggest quacks are actually doctors themselves. (P_48)

Common examples of inappropriate use of antibiotics by HCPs included the following: for a common cold or diarrhoea, given unnecessarily as prophylaxis during surgery or after normal vaginal delivery, adding multiple antibiotics because of a presumed additive effect on efficacy or because of lack confidence about which antibiotic will work, and incorrect dosing.

Relating our results back to our conceptualisation of $\mathrm{HCP}$ professionalism, we first discuss the findings about the two components of competence (technical knowledge on use of antibiotics followed by a collaboration with other HCPs), and then about the two components of care (altruism, professional ethics, and conflict of interest followed by communication).

\section{Technical knowledge on when and how to use antibiotics} imparted during initial HCP education

Ten interviewees in Pakistan and five in Cambodia attributed the widespread inappropriate use of antibiotics partly to weaknesses in the quality of knowledge imparted during HCP education.

First thing that should be done is to send them back to school. Raising awareness. (C_1)

Two critical gaps in the curriculum and training programmes highlighted were inadequate coverage of AMR/microbiology and a scarcity of education on the appropriate use of antibiotics, and lack of attention to preventative measures such as infection control and vaccination. Discussing the latter, some interviewees suggested that HCPs realised that insufficient infection control measures were being taken in health facilities and homes and that this drove them to overuse antibiotics to compensate. We found that the insufficient emphasis on AMR during initial HCP education may be responsible for a perception among HCPs (as reported by them and interviewees who had audited prescribing patterns) that antibiotics can be used for a range of conditions without needing a specific diagnosis and that AMR is not a serious concern because there are other antibiotics available if resistance develops to one:

Definitely, our healthcare professionals are not aware of AMR. They don't bother, they don't care about it. To them they have got many options [of antibiotics] (P_35)

Because of the widespread feeling that HCP education is inadequate and that qualified and unqualified HCPs are therefore similar in their technical knowledge, many interviewees felt that qualified HCPs would not always act as good gatekeepers for access to medicines such as antibiotics. There were some differences in the perceived value of HCP education between the two study countries. In Cambodia, four interviewees indicated that qualified HCPs were more aware of the responsibilities around prescribing than non-qualified HCPs. However, in Pakistan, three interviewees said that GPs learn from the incorrect behaviour of specialists and that drug sellers learn from observing the incorrect prescriptions of doctors. Furthermore, one senior clinical microbiologist in Pakistan described a vicious cycle in which hospitals and public health institutions do not want to pay higher salaries to recruit qualified HCPs since they know that the training is inadequate, and this further devalues HCP education institutions (P_20).

\section{Collaborating with other HCPs}

A clear and consistent finding in both countries was the lack of respect for the skills and specific roles of doctors, pharmacists, nurses, midwives, and drug sellers, such that each category of HCPs was taking on the roles of others in order to maximise profits. For instance, there was consensus in both countries that doctors not only diagnose patients but also sell medicines to them; this diminishes the role and income of pharmacists and drug sellers. Pharmacists and drug sellers also encroach upon the doctors' role by diagnosing patients after listening to their symptoms and then selling medicines that should only be available with a prescription. One interviewee in Pakistan, a government official, expressed concern that pharmacists are not only taking on the roles of doctors in their interactions with patients but that some tell patients that they are medical doctors as their Doctor of Pharmacy degree allows them to use the title of doctor (P_32). A pharmaceutical company employee in Cambodia explained that it is not financially viable for pharmacists to only dispense antibiotics when patients bring a prescription: If I have my own pharmacy and wait for [a] prescription, then probably I will die (C_20). We also found, in both countries, that the years of training undertaken by pharmacists often led to them being perceived as 'overqualified' to be selling medicines in pharmacies, as this was a role played by drug sellers (with limited professional education); we found that several, but not all, pharmacists used their professional licences to set up pharmacies that they did not work at. 


\section{Altruism, professional ethics, and conflict of interest} Our analysis revealed that a critical element of HCP education-professional ethics and cognisance about conflicts of interest-was inadequate among many HCPs in both countries. It was common for HCPs to run healthcare facilities primarily as businesses, and the influence of the profit-making element of patient consultations on HCPs' professional judgement was not typically inculcated during training. Therefore, while most HCPs were not concerned about conflicts of interest that could drive providerinduced demand for antibiotics, several policymakers believed that this is a major issue that should be addressed by increasing professional ethics training.

Do you think they bother about this AMR? They just bother about their earning. (P_35)

We cannot wait for the law. All the physicians after they finish [professional education], they should have medical ethics. Understand their role. (C_13)

In particular, we documented an entrenched acceptance of gifts and 'continuing medical education' from pharmaceutical companies by HCPs, with inadequate questioning of conflicts of interest. The role of pharmaceutical companies in influencing antibiotic use was confirmed by 18 policymakers, HCPs, and pharmaceutical companies in Pakistan and Cambodia. The incentives provided include free medicines (buy 10 get one free), or direct payments/gifts for selling an agreed volume of antibiotics. Although few policymakers and NGO representative referred to the latter as 'bribes', they agreed that these unethical practices were common in both countries. Indeed, we found in Pakistan that some companies may have consciously designed incentive packages that counteract questions raised about the ethics of direct incentives provided for selling medicines, by paying for doctors to go on religious pilgrimages to Saudi Arabia.

Another common benefit given to HCPs by pharmaceutical companies, particularly doctors, was access to scientific information about new medicines or a medical condition, either by visiting the doctor's clinic or by inviting the doctor to an expensive hotel or overseas destination. This strategy often appeared more benign to HCPs than a direct financial incentive for selling an agreed volume of antibiotics. However, it was highlighted that doctors were given trips to attractive destinations-often linked to meeting prescribing targets-under the guise of 'continuing medical education'. Medical education seminars sponsored by pharmaceutical companies were clearly popular in both countries, partly because they fill a serious gap in the CME opportunities, which were described as extremely limited and under-developed. It was clear from our analysis that
HCPs in both countries paid insufficient attention to conflicts of interest that pharmaceutical companies might have when imparting 'scientific information'.

\section{Communication}

The majority of interviewees in both countries indicated that it is common for patients to expect or demand antibiotics from doctors, pharmacists, and drug sellers. While some HCPs' inappropriate use of antibiotics stems from their lack of knowledge, as presented earlier, our findings suggest that others know that antibiotics should not be dispensed but have not gained critical communication skills during their training to be able to counsel patients appropriately. Instead, doctors in both countries were reported to feel anxious about being perceived by patients as 'a D grade doctor' or about losing future business if they do not give enough medication following a consultation.

Out of 10 consumers, 9 won't listen to us and they buy what they want. When we advise them, they do not listen to us. Some consumers feel that we want to prescribe drugs for a long duration so that we can make more money (C_29, pharmacist)

A striking finding in both countries was that some HCPs give third-generation antibiotics that patients have not heard of in order to gain patients' confidence and to appear more knowledgeable. When we presented our initial findings in Cambodia, one clinical and policy advisor on AMR (C_1) strongly emphasised the need for improvements in HCP communication skills to tackle patient demand for antibiotics. Similarly, a well-respected infectious disease specialist in Pakistan stated that lack of HCP communication skills was responsible for the (perceived) strong patient demand for antibiotics:

you know this is an excuse that the most doctors give [for inappropriate antibiotic use] that the patients demand it ...they need your time, they need your explanations and once you secure their confidence they'll never insist on anything. (P_14).

\section{Discussion}

Based on our findings, we make the potentially contentious assertion that when global guidelines recommend that patients should only seek care at qualified HCPs, it is essential to ensure that HCP qualifications are equipping them to act in the best interest of the patient and society. Our investigation of HCP professionalism, through examining inappropriate use of antibiotics in Pakistan and Cambodia, suggests that this will be a long process. We identified five areas in which strengthening of HCP education could reduce inappropriate use of 
antibiotics and thereby enhance the social benefits provided by HCPs. These were delivering better teaching about the need for appropriate use of medicines and antibiotics specifically; imparting stronger communication skills to deal with patient demand for antibiotics; inculcating professional ethics; providing skills required for effective collaboration between doctors, pharmacists, and lay HCPs such as drug sellers; and ensuring access to (unbiased) CME. Strengthening of HCP education would also ideally include an emphasis on working across sectors and disciplinary boundaries, for example, to the interconnectedness of human health, animal health, and the environment $[53,54]$.

The WHO and others have emphasised the social mission of HCP educational institutions $[4,6]$ and that a crucial part of this culture of neglect is a failure to appreciate the importance of universities as core social institutions that require appropriate regulation [1]. However, it is important to consider whether there are any incentives for HCP education institutions and their students to focus on social accountability, and to assess the extent to which HCPs demonstrate attributes of professionalism, as we do in this study. Concerns have been raised about whether notions about the social mission of healthcare provision may be idealistic and out of touch with the goals of young people who are primarily seeking to earn sufficient income. For example, in Pakistan, a decrease in the proportion of men applying to medical school has been attributed to the relatively low income of doctors [55].

Although strong HCP education that builds upon the components of professionalism we have discussed is essential, we recognise that other dynamics driving inappropriate use of antibiotics are also important to tackle [56]. For example, addressing unethical marketing practices that pharmaceutical companies use to incentivise HCPs is required in addition to a greater emphasis on professional ethics in HCP education [57]. It is also crucial to acknowledge that HCPs often seek additional income or rely on other sources of job motivation because public sector salaries in LMIC are low, and income during clinical training years is typically minimal [58-62]. Finally, low access to affordable diagnostics, and the need for many poor patients earning a daily wage to return to work quickly, will continue to play a role in HCP's decision-making [17]. Without addressing some of these systemic drivers of inappropriate use of medicines, teaching the values related to professionalism may not translate into behavioural change. Similarly, a conducive regulatory environment is critical, and generating the resources and political will to implement regulations that address poor quality of healthcare is often very challenging $[63,64]$.
We acknowledge that a limitation of our study is that we were only able to conduct such an in-depth investigation in two countries, and further research would be required to assess the applicability of our findings to other contexts. Our findings about the potential conflicts of interest arising from the relationship between pharmaceutical companies and doctors could be triangulated by non-participant observations at sponsored continuing medical education seminars and during marketing visits by pharmaceutical sales representatives. We appreciate that our views and judgements as researchers may have influenced our interpretations. However, published literature supports our observations, concluding that professional education in many Asian countries has not kept pace with new technologies, societal demands, and health system dynamics related to the growth of informal and private HCPs, because of outdated curricula and poor enforcement of standards [47, 65]. Furthermore, some of the components we identified which require strengthening in HCP education, such as learning communication skills to reassure patients that they do not need an antibiotic, are also relevant to higherincome countries; for example, there was a dramatic reduction in antibiotic prescribing when GPs in the Netherlands received training in enhanced communication skills [66], and a systematic review of physiciantargeted interventions to improve antibiotic use for respiratory tract infections identified communication skills training as the most promising [67].

\section{Conclusion}

It is often assumed that increasing access to qualified HCPs will be beneficial to patients and to society because qualified HCPs will demonstrate more competence and care than unqualified HCPs when delivering clinical services. Our study provides evidence from two diverse countries indicating that HCP professional education may not be equipping HCPs with essential skills and values to ensure that they act in the patient's best interest when providing antibiotics. Although HCP educational institutions are not presently held to account for the ways in which their graduates serve their societies, we question whether such accountability should be required, particularly in light of the increase in private medical institutions in many LMIC. Finally, we conclude that the specific improvements to HCP education that we have identified are particularly pertinent for LMIC contexts, since self-regulation of HCPs plays a critical role when government ability to enforce rules is lacking $[68,69]$.

\section{Abbreviations}

AMR: Antimicrobial resistance; CMC: Cambodia Medical Council; CME: Continuing Medical Education; HCP: Healthcare provider; LMIC: Lowand middle-income country; PMDC: Pakistan Medical and Dental Council 


\section{Acknowledgements}

We would like to acknowledge Dr. S. Ly for his impeccable focus group facilitation in Cambodia. We would like to thank the many participants from Pakistan and Cambodia who took the time to help us understand these complex issues.

\section{Authors' contributions}

All the authors were involved in the design of the study and reviewed the paper. MK, SB, and SR wrote the first draft. SS, ADB, SP, SC, CP, SH, ZS, and $\mathrm{RH}$ participated in the data collection and analysis. All authors read and approved the final manuscript

\section{Funding}

This research was funded by a Medical Research Council Joint Health Systems Research Initiative Foundation Grant (MR/R003467/1) and an Economic and Social Research Council grant (ES/P003842/1).

\section{Availability of data and materials}

The datasets generated and/or analysed during the current study are not publicly available but are available from the corresponding author on reasonable request.

\section{Ethics approval and consent to participate}

This study received ethical approval from the London School of Hygiene and Tropical Medicine and the Cambodia National Ethics Committee for Health Research (NECHR). Written informed consent was taken before conducting the interviews or FGDs. Since some of the HCPs we interviewed may have been contravening regulations by selling medicines, we do not name the communities selected for the data collection to protect the anonymity of respondents.

\section{Consent for publication}

Not applicable.

\section{Competing interests}

The authors declare that they have no competing interests.

\section{Author details}

${ }^{1}$ Faculty of Public Health \& Policy, London School of Hygiene \& Tropica Medicine, 15-17 Tavistock Place, London WC1H 9SH, United Kingdom. ${ }^{2}$ Aga Khan University, Karachi, Pakistan. ${ }^{3}$ Faculty of Pharmacy, University of Health Sciences, Phnom Penh, Cambodia. ${ }^{4}$ Department of Public Health, University of Health Sciences, Phnom Penh, Cambodia. ${ }^{5}$ University of Health Sciences, Phnom Penh, Cambodia. ${ }^{6}$ Faculty of Infectious and Tropical Diseases, London School of Hygiene \& Tropical Medicine, London, United Kingdom.

\section{Received: 7 November 2019 Accepted: 30 January 2020}

\section{Published online: 11 February 2020}

\section{References}

1. Horton R. A new epoch for health professionals' education. Lancet. 2010; 376(9756):1875-7. https://doi.org/10.1016/S0140-6736(10)62008-9.

2. Ghaffar A, Zaidi S, Qureshi H, et al. Medical education and research in Pakistan. Lancet. 2013;381(9885):2234-6. https://doi.org/10.1016/S01406736(13)60146-4

3. Crisp N, Chen L. Global supply of health professionals. N Engl J Med. 2014; 370(10):950-7.

4. WHO. Global strategy on human resources for health: workforce 2030. 2016.

5. Kanchanachitra $C$, Lindelow $M$, Johnston $T$, et al. Human resources for health in Southeast Asia: shortages, distributional challenges, and international trade in health services. Lancet. 2011;377(9767):769-81. https:// doi.org/10.1016/S0140-6736(10)62035-1.

6. Frenk J, Chen L, Bhutta ZA, et al. Health professionals for a new century: transforming education to strengthen health systems in an interdependent world. Lancet. 2010;376(9756):1923-58. https://doi.org/10.1016/S01406736(10)61854-5

7. WHO. A universal truth: no health without a workforce: Global Health Workforce Alliance (GHWA) Secretariat and the World Health Organization (WHO), 2013.
8. Haque MS, Abdus HA, Islam Z, et al. Comparative study on professionalism of forthcoming medical doctors between two private medical college in Savar, Bangladesh. Int Symp Health Sci. 2013;5(3):659-65.

9. Leonard KL, Masatu MC. Professionalism and the know-do gap: exploring intrinsic motivation among health workers in Tanzania. Health Econ. 2010; 19(12):1461-77. https://doi.org/10.1002/hec.1564 Published Online First: 2009/12/05

10. Latif MZ, Wajid G. Reforming medical education in Pakistan through strengthening departments of medical education. Pak J Med Sci. 2018;34(6): 1439-44. https://doi.org/10.12669/pjms.346.15942.

11. Boelen C, Woollard B. Social accountability and accreditation: a new frontier for educational institutions. J Med Educ. 2009;43(9):887-94.

12. Hamill $\mathrm{H}$, Hampshire $\mathrm{K}$, Mariwah $\mathrm{S}$, et al. Managing uncertainty in medicine quality in Ghana: the cognitive and affective basis of trust in a high-risk, low-regulation context. Soc Sci Med. 2019;234:112369.

13. Bateman C, Baker T, Hoornenborg $\mathrm{E}$, et al. Bringing global issues to medical teaching. Lancet. 2001;358(9292):1539-42.

14. Crisp N. Global health capacity and workforce development: turning the world upside down. Infect Dis Clin. 2011;25(2):359-67.

15. WHO. Global action plan on antimicrobial resistance. Geneva: World Health Organization; 2015.

16. WHO. In: Lewis S, editor. Turning plans into actions for antimicrobial resistance (AMR), Working Paper 2.0: Implementation and coordination. Geneva: World Health Organization; 2019.

17. Bloom G, Standing H. Pluralism and marketisation in the health sector: meeting health needs in contexts of social change in low and middleincome countries. Working paper series, 136. IDS: Brighton; 2001.

18. Gryseels C, Kuijpers LMF, Jacobs J, et al. When 'substandard' is the standard, who decides what is appropriate? Exploring healthcare provision in Cambodia. Crit Public Health. 2019;29(4):460-72. https://doi.org/10.1080/ 09581596.2019.1591614.

19. Kwan A, Daniels B, Saria V, et al. Variations in the quality of tuberculosis care in urban India: a cross-sectional, standardized patient study in two cities. PLoS Med. 2018:15(9):e1002653. https://doi.org/10.1371/journal.pmed.1002653.

20. Suy S, Rego S, Bory S, et al. Invisible medicine sellers and their use of antibiotics: a qualitative study in Cambodia. BMJ Glob Health. 2019:4(5): e001787. https://doi.org/10.1136/bmjgh-2019-001787.

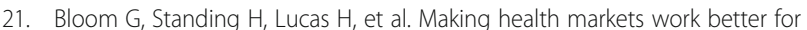
poor people: the case of informal providers. Health Policy Plann. 2011; 26(suppl_1):i45-52. https://doi.org/10.1093/heapol/czr025.

22. Irby DM, Hamstra SJ. Parting the clouds: three professionalism frameworks in medical education. Acad Med. 2016;91(12):1606-11.

23. Phillips SP, Dalgarno N. Professionalism, professionalization, expertise and compassion: a qualitative study of medical residents. BMC Med Educ. 2017; 17(1):21.

24. Irby DM. Constructs of professionalism. Medical professionalism best practices: professionalism in the modern era. Aurora, Colorado: Alpha Omega Alpha Honor Medical Society; 2017. p. 9.

25. Monrouxe LV, Rees CE. Healthcare professionalism: improving practice through reflections on workplace dilemmas. Hoboken: Wiley; 2017. https:// doi.org/10.1002/9781119044475.

26. Wilkinson TJ, Wade WB, Knock LD. A blueprint to assess professionalism: results of a systematic review. Acad Med. 2009:84(5):551-8.

27. Brody H, Doukas D. Professionalism: a framework to guide medical education. Med Educ Rev. 2014:48(10):980-7.

28. Lucey CR. Is medical education a public or a private good? Insights from the numbers. J Am Med Assoc. 2017:318(23):2303-5.

29. Relman AS. Medicine as a profession and a business. In: The Tanner Lectures on Human Values; 1986. p. 283-313.

30. General Population Census of the Kingdom of Cambodia 2019. Provisional population totals: National Institute of Statistics and Ministry of Planning; 2019. p. 6-7.

31. Grundy J, Khut QY, Oum S, et al. Health system strengthening in Cambodiaa case study of health policy response to social transition. Health Policy. 2009:92(2-3):107-15. https://doi.org/10.1016/j.healthpol.2009.05.001 Published Online First: 2009/06/09.

32. Zaidi S, Bigdeli $M$, Aleem $N$, et al. Access to essential medicines in Pakistan: policy and health systems research concerns. PLoS One. 2013;8(5):e63515. https://doi.org/10.1371/journal.pone.0063515.

33. WHO. Out-of-pocket expenditure as percentage of current health expenditure (CHE) 2017. Available from: http://apps.who.int/gho/data/node. main.GHEDOOPSCHESHA2011?lang=en. 
34. WHO. Health Service Delivery Profile Cambodia. Cambodia: WHO and Ministry of Health; 2012.

35. WHO. WHO Global Health Expenditure Database WHO; Available from: http:// apps.who.int/nha/database/Select/Indicators/en2019. Accessed Nov 2019.

36. Trankell IB, Ovesen J. French colonial medicine in Cambodia: reflections of governmentality. Anthropol Med. 2004;11(1):91-105. https://doi.org/10.1080/ 1364847042000204898

37. Millet $P$, Bounchan $Y$, Phuong $P$, et al. Retrospective analysis of medical practice training in French public hospitals of Cambodian medical specialists and pharmacy professionals and students enrolled at the University of Health Sciences of Cambodia between 1996 and 2016. J Medic Educ Train. 2018;2(1). http//uww. scientificoajournals.org/medical-education-currentissue.php.

38. Guillou AY. Medicine in Cambodia during the Pol Pot regime (1975-1979). New York: East Asian Medicine under Communism: A Symposium City University of New York; 2004

39. Sothy K, Madhur S, Rethy C. Cambodia Education 2015: employment and empowerment. Phnom Penh: Cambodia Development Resource Institute; 2015

40. Santini H. Rebirth of the health-care system in Cambodia. Lancet. 2002;360: s57-8. https://doi.org/10.1016/S0140-6736(02)11824-1.

41. Presentation on Health Sector Achievement in Cambodia in 2018. Conference on Ministry of Health Achievement: Ministry of Health, 2019. http://moh.gov.kh/content/uploads/2017/05/2019_MoH-Final01-Low.pdf.

42. Amaro Y. Building a medical system without a foundation? The Phnom Penh Post; 2016.

43. Chansy C, Reuy R. Failed medical students protest against examination results. The Cambodia Daily; 2009

44. Reuy R. Students protest altered admission regulations. The Cambodia Daily; 2008.

45. UHS at a glance: University of Health Sciences; 2015. Available from: http:// www.uhs.edu.kh/ir/2019. Accessed Nov 2019.

46. Council PMD. Recognized Medical Colleges in Pakistan. Available from: http://www.pmdc.org.pk/AboutUs/RecognizedMedicalDentalColleges/ tabid/109/Default.aspx2019. Accessed Nov 2019.

47. Amin Z, Burdick WP, Supe A, et al. Relevance of the Flexner Report to contemporary medical education in South Asia. Acad Med. 2010;85(2):333-9.

48. Sabzwari SR. The case for family medicine in Pakistan. J Pak Med Assoc. 2015;65(6):660-4.

49. Shaikh SH. A reform agenda outline for medical education. Pak J Coll Physicians Surg Pak. 2009;19(6):331-2.

50. CPSP. Continuing Medical Education College of Physicians and Surgeons Pakistan; 2019. Available from: https://www.cpsp.edu.pk/cme.php.

51. O'Brien BC, Harris IB, Beckman TJ, et al. Standards for reporting qualitative research: a synthesis of recommendations. Acad Med. 2014;89(9):1245-51. https://doi.org/10.1097/acm.0000000000000388.

52. Rice PL. Qualitative research methods : a health focus/Pranee Liamputtong Rice and Douglas Ezzy. Melbourne: Oxford University Press; 1999.

53. Jasani S. Using a one health approach can foster collaboration through transdisciplinary teaching. Medical Teacher. 2019;41(7):839-41. https://doi. org/10.1080/0142159X.2018.1484080.

54. Nandiwada DRC, Dang-Vu. Transdisciplinary health care education: training team players. J Health Care Poor Underserved. 2010;21(1):26-34. https://doi.org/10. 1353/hpu.0.0233

55. Biggs JS. Postgraduate medical training in Pakistan: observations and recommendations. J Coll Phys Surg Pak. 2008;18(1):1-2.

56. Legido-Quigley H, Khan MS, Durrance-Bagale A, et al. Something borrowed something new: a governance and social construction framework to investigate power relations and responses of diverse stakeholders to policies addressing antimicrobial resistance. Antibiotics (Basel). 2018;8(1). https://doi.org/10.3390/ antibiotics8010003 Published Online First: 2018/12/28

57. de Andrade M, Jafarey A, Shekhani SS, et al. The ethics of pharma-physician relations in Pakistan: "when in Rome". Ethics Behav. 2019;29(6):473-89. https://doi.org/10.1080/10508422.2018.1481751.

58. Khan MS, Roychowdhury I, Meghani A, et al. Should performance-based incentives be used to motivate health care providers? Views of health sector managers in Cambodia, China and Pakistan. Health Econ Policy Law. 2019:1-14. https://doi.org/10.1017/s1744133118000506 Published Online First: 2019/02/01

59. Khan MS, Mehboob N, Rahman-Shepherd A, et al. What can motivate Lady Health Workers in Pakistan to engage more actively in tuberculosis casefinding? BMC Public Health. 2019;19(1):999. https://doi.org/10.1186/s12889019-7326-8 Published Online First: 2019/07/28.
60. Chhea C, Warren N, Manderson L. Health worker effectiveness and retention in rural Cambodia. Rural Remote Health. 2010;10(3):1391 Published Online First: 2010/08/13.

61. Henderson LN, Tulloch J. Incentives for retaining and motivating health workers in Pacific and Asian countries. Hum Resour Health. 2008;6(1):18 https://doi.org/10.1186/1478-4491-6-18.

62. Mir AM, Shaikh MS, Rashida G, et al. To serve or to leave: a question faced by public sector healthcare providers in Pakistan. Health Res Policy Syst. 2015;13(1):S58. https://doi.org/10.1186/s12961-015-0045-4.

63. Khan MS, Hashmani FN. Political and technical barriers to improving quality of health care. Lancet. 2018;392(10160):2146-7. https://doi.org/10.1016/ S0140-6736(18)32075-0.

64. Khan MS, Salve S, Porter JD. Engaging for-profit providers in TB control: lessons learnt from initiatives in South Asia. Health Policy Plan. 2015;30(10): 1289-95. https://doi.org/10.1093/heapol/czu137 Published Online First: 2015/01/22.

65. Supe A, Burdick W. Challenges and issues in medical education in India. Acad Med. 2006;81(12):1076-80.

66. Cals JW, Butler CC, Hopstaken RM, et al. Effect of point of care testing for C reactive protein and training in communication skills on antibiotic use in lower respiratory tract infections: cluster randomised trial. BMJ. 2009;338:b1374.

67. van der Velden AW, Pijpers EJ, Kuyvenhoven MM, et al. Effectiveness of physician-targeted interventions to improve antibiotic use for respiratory tract infections. Br J Gen Pract. 2012;62(605):e801-e07.

68. Knox C. Dealing with sectoral corruption in Bangladesh: developing citizen involvement. Int J Manag Res Pract. 2009;29(2):117-32. https://doi.org/10. 1002/pad.523

69. Pillay P, Mantzaris EA. Corruption in the health sector in South Africa and India: some considerations and reflections. Afr J Public Aff. 2017;9(8):48-62.

\section{Publisher's Note}

Springer Nature remains neutral with regard to jurisdictional claims in published maps and institutional affiliations.
Ready to submit your research? Choose BMC and benefit from:

- fast, convenient online submission

- thorough peer review by experienced researchers in your field

- rapid publication on acceptance

- support for research data, including large and complex data types

- gold Open Access which fosters wider collaboration and increased citations

- maximum visibility for your research: over $100 \mathrm{M}$ website views per year

At $\mathrm{BMC}$, research is always in progress.

Learn more biomedcentral.com/submissions 